\title{
Protease-Resistant Peptides for Targeting and Intracellular Delivery of Therapeutics
}

\author{
Maria C. Lucana, Yolanda Arruga, Emilia Petrachi, Albert Roig, Roberta Lucchi and Benjamí Oller-Salvia *D \\ Grup d’Enginyeria de Materials (GEMAT), Institut Químic de Sarrià (IQS), Universitat Ramon Llull, \\ 08017 Barcelona, Spain; marialucanam@iqs.url.edu (M.C.L.); yolandaarrugat@iqs.url.edu (Y.A.); \\ emilia.petrachi@iqs.url.edu (E.P.); albertroigm@iqs.url.edu (A.R.); roberta.lucchi@iqs.url.edu (R.L.) \\ * Correspondence: benjami.oller@iqs.url.edu
}

Citation: Lucana, M.C.; Arruga, Y.; Petrachi, E.; Roig, A.; Lucchi, R.; Oller-Salvia, B. Protease-Resistant Peptides for Targeting and Intracellular Delivery of Therapeutics. Pharmaceutics 2021, 13, 2065. https://doi.org/10.3390/ pharmaceutics 13122065

Academic Editor: Giancarlo Morelli

Received: 3 November 2021

Accepted: 24 November 2021

Published: 2 December 2021

Publisher's Note: MDPI stays neutral with regard to jurisdictional claims in published maps and institutional affiliations.

Copyright: (C) 2021 by the authors. Licensee MDPI, Basel, Switzerland. This article is an open access article distributed under the terms and conditions of the Creative Commons Attribution (CC BY) license (https:/ / creativecommons.org/licenses/by/ $4.0 /)$.
Abstract: Peptides show high promise in the targeting and intracellular delivery of next-generation bio- and nano-therapeutics. However, the proteolytic susceptibility of peptides is one of the major limitations of their activity in biological environments. Numerous strategies have been devised to chemically enhance the resistance of peptides to proteolysis, ranging from $\mathrm{N}$ - and $\mathrm{C}$-termini protection to cyclization, and including backbone modification, incorporation of amino acids with non-canonical side chains and conjugation. Since conjugation of nanocarriers or other cargoes to peptides for targeting and cell penetration may already provide some degree of shielding, the question arises about the relevance of using protease-resistant sequences for these applications. Aiming to answer this question, here we provide a critical review on protease-resistant targeting peptides and cell-penetrating peptides (CPPs). Two main approaches have been used on these classes of peptides: enantio/retro-enantio isomerization and cyclization. On one hand, enantio/retro-enantio isomerization has been shown to provide a clear enhancement in peptide efficiency with respect to parent L-amino acid peptides, especially when applied to peptides for drug delivery to the brain. On the other hand, cyclization also clearly increases peptide transport capacity, although contribution from enhanced protease resistance or affinity is often not dissected. Overall, we conclude that although conjugation often offers some degree of protection to proteolysis in targeting peptides and CPPs, modification of peptide sequences to further enhance protease resistance can greatly increase homing and transport efficiency.

Keywords: targeting peptides; cell-penetrating peptides; protease resistance; proteolysis; enantio; retro-enantio; retro-inverso; cyclic peptides

\section{Introduction}

Targeted therapeutics are changing the established medical paradigm. This type of therapeutics is capable of selectively affecting desired cells, thereby dramatically reducing side effects. Although monoclonal antibodies have been the basis for the most successful targeted therapies until now, several alternatives are arising. In order to increase tissue selectivity of nano- and biotherapeutics other than antibodies, many efforts are devoted to exploring more accessible targeting moieties such as small molecules and peptides. Peptides, which are defined by the FDA as polymers composed of 40 or fewer amino acids [1], lie between small molecules and biotherapeutics and can combine the best of the two worlds. Similar to antibodies, peptides may possess a high affinity and selectivity, and, like small molecules, they are synthetically accessible, easy to derivatize, and generally have low immunogenicity. Moreover, peptides with particular physicochemical properties may help nano- and biotherapeutics cross the cell membrane, which is the ultimate barrier to achieving intracellular activity.

The main obstacles towards widespread applications of peptides are their rapid renal clearance and their susceptibility to proteolytic degradation. While the former is a concern 
for stand-alone peptide therapeutics, it is not a major problem when conjugated to protein therapeutics or nanomedicines. Conversely, proteolysis presents a potential problem to be addressed in any kind of peptide, either conjugated or not. The cause of the rapid degradation of peptides is the presence of endogenous proteases, which are enzymes that catalyze the hydrolysis of peptide bonds. Exoproteases attack terminal amino acids, while endoproteases may recognize motifs inside the peptide sequences and hydrolyze internal peptide bonds [2]. As a consequence, most linear peptides with all-L amino acids have a half-life of 5-30 min in serum [3], which would appear insufficient to enable efficient targeting, especially of large therapeutics.

Since many all-L linear peptides have successfully been used to target cargoes to several tissues [4], one might expect that the cargo molecule would offer some degree of protection against proteolysis due to steric hindrance. Despite the extensive literature describing peptides used as targeting and cell-penetrating moieties, little information is available about how peptide conjugation protects them from protease degradation. Hence, the question arises about the extent to which increasing the metabolic resistance of targeting peptides is relevant in conjugated peptides. Aiming to answer this question, we critically reviewed the recent literature and selected relevant examples to discuss the influence of peptide resistance to proteases in their targeting or cell penetration capacity. Herein, we first summarize the main strategies for increasing peptide resistance to proteases. Then, we focus on the two main strategies used to enhance stability in targeting and cell-penetrating peptides. Throughout the review, we illustrate with many examples how making peptides protease-resistant further boosts their targeting and transport efficiency.

\section{Peptide Resistance to Proteases May Be Enhanced through a Variety of Chemical Modifications}

Strategies for enhancing the resistance of peptides to proteases range from protection of $\mathrm{N}$ - and $\mathrm{C}$-termini to conjugation, including backbone modification, incorporation of alpha amino acids with non-canonical side chains, and cyclization [5] (Figure 1). A combination of more than one strategy is also frequently used [6]. Peptides with such modifications can be included within the broad classification of "peptidomimetics" [7].

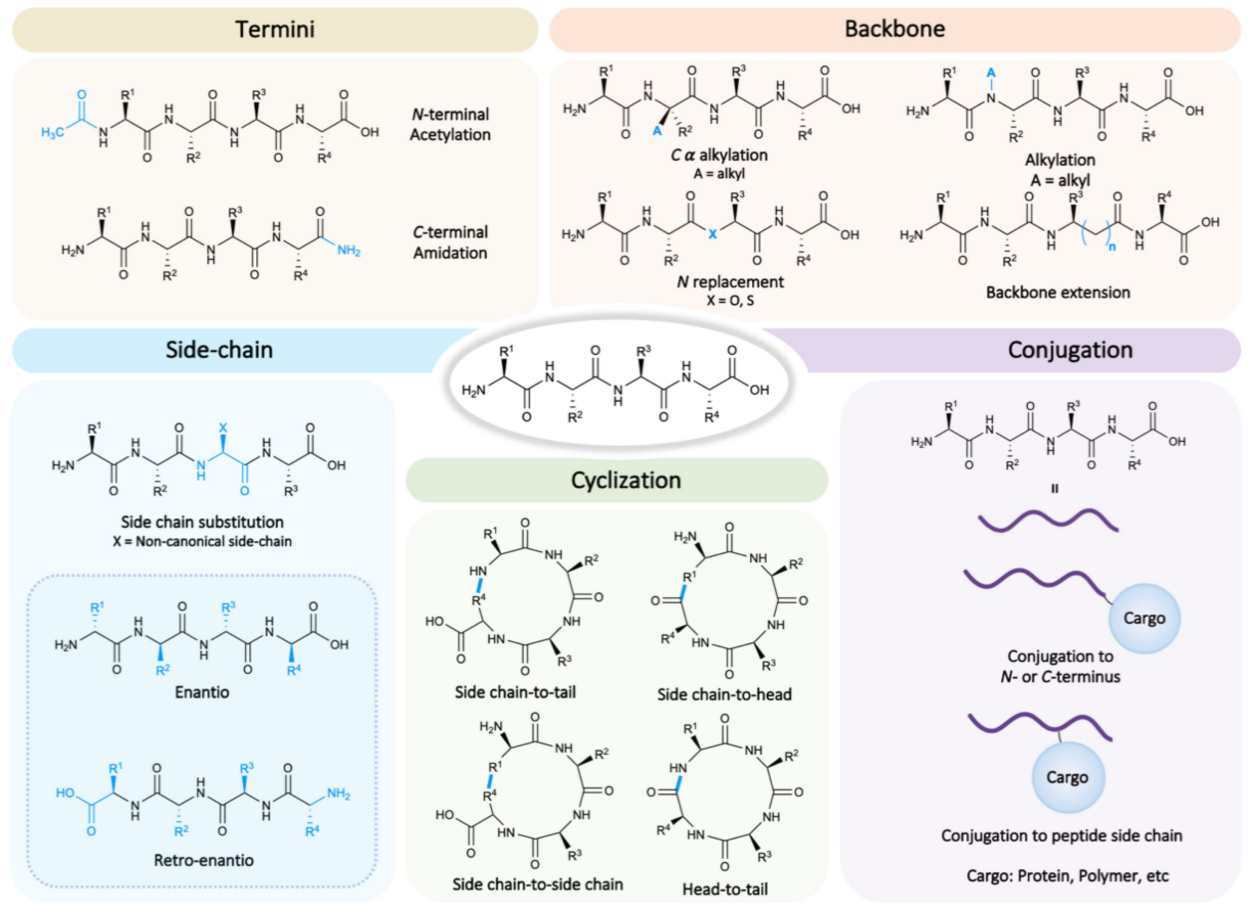

Figure 1. A plethora of strategies for enhancing peptide resistance to proteases have been developed. 


\section{1. $\mathrm{N}$ - and C-Termini}

The most basic form of protection is to modify the $N$ - and $C$-termini of the peptide, thereby reducing recognition by exoproteases, i.e., aminopeptidase and carboxypeptidase. Although most commonly the $\mathrm{N}$-terminus is acetylated and the $\mathrm{C}$-terminus is amidated, many other modifications hinder exoprotease-mediated hydrolysis [8].

\subsection{Backbone}

Aiming to extend the protection to endoproteases, the alpha amino acid backbone can be modified [9]. These peptidomimetic molecules can be generated via modifications such as isosteric replacement of amide bonds, amide alkylation, and carbon skeleton extension, among others [10]. The bioisosteric replacement consists in exchanging the amide bond for groups with similar biological properties such as esters (depsipeptides), thioesters (thiodepsipeptides), or even triazole groups. Other examples of modifications that can be performed to a natural peptide backbone are $\alpha$-methylation and $N$-methylation. While $\alpha$-methylation of amino acids rigidifies the peptide structure and has an effect on the peptide dihedral angles, which is especially critical in helical peptides, $\mathrm{N}$-methylation decreases hydrogen bond formation and increases lipophilicity, thereby enhancing the peptide capacity to cross biological barriers [11]. The backbone can also be modified using $\beta$ or $\gamma$ amino acid residues, which extend the carbon skeleton and expand conformation and folding possibilities [10].

\subsection{Side Chains}

An alternative to backbone modification for decreasing potentially both endo- and exoprotease recognition is the incorporation of amino acid residues with non-canonical side chains. There is a wide range of possible side chain modifications that have been found in nature or produced synthetically [12-14]. The most relevant family of non-canonical amino acids in targeting and cell-penetrating peptides is the family of D-enantiomeric amino acid residues. Peptides that are entirely composed of D-amino acids are generally known as "enantio" or "inverso" peptides. This kind of peptide has attracted increasing interest, owing to its high resistance to proteolytic degradation under physiological conditions [15]. Since the D-peptide shows different side chain orientation with respect to the parent Lpeptide, target engagement may decrease if such binding depends on the 3D structure of the peptide. Combining enantio isomerization with reversing the peptide sequence results in the "retro-inverso" or "retro-enantio" isomer of the peptide (Figure 1, bottom left). The retro-enantio peptide displays a side chain topology similar to that of its native L-form with inverted amide bonds. For small peptides that do not depend heavily on tertiary structures, the retro-enantio isomer may have similar biological activity to the parent molecules, while presenting full resistance to proteolytic degradation [16]. Moreover, non-natural amino acids such as D-amino acids may decrease potential immunogenicity [17].

\subsection{Cyclization}

While modification of peptide side chains, backbone, and termini can provide outstanding resistance to proteolytic degradation, they often result into lower peptide affinity. Conversely, cyclization may increase not only hydrolytic stability but also binding to the target protein [18-22]. Cyclic peptides often show improved biological activity compared with their linear counterparts since the active conformation can be favored, thereby decreasing the entropic component in binding [23]. In addition, the constraint induced by cyclization decreases the probability of a good fit in the active site of endoproteases [5]. This shielding against enzymatic hydrolysis is highly efficient in short cyclic peptides and in longer sequences in which secondary structures, such as turns, helices, and sheets, are stabilized by the cyclization [20]. Amide bonds that are part of a hydrogen-bonding network, as in stapled peptides, are particularly poor enzymatic substrates [24]. Furthermore, most cyclizations are also designed to involve the terminal residues; therefore, they also protect the peptide from exoproteases [25]. Depending on the peptide structural context, several 
cyclization strategies can be applied: head-to-tail, side chain-to-head, side chain-to-tail and side chain-to-side chain [5]. A plethora of chemistries have been developed for cyclization, ranging from natural disulfide bridges or isopeptide bonds to metal-catalyzed ring-closing metathesis (RCM), as well as azide-alkyne and Diels-Alder cycloadditions [26,27]. Moreover, peptide conformations may be further constrained by multicyclization and the use of chemical scaffolds to mediate linkage [28].

\subsection{Conjugation}

An alternative way of enhancing peptide resistance to proteases is via conjugation to another molecule or nanoparticle. This potential protection mode is intrinsic to targeting and cell-penetrating peptides that transport cargoes. It seems intuitive that the conjugation of the peptide will provide steric hindrance and decrease proteolytic degradation. However, although many studies have demonstrated and increased half-life upon conjugation to large carriers such as polyethylene glycol, antibody constant fragment, or nanoparticles, few analyze the integrity or function of the peptide with time. The conjugation site in the peptide is crucial for maximizing activity and minimizing proteolytic degradation, not only because different regions of the peptide are protected but also because conjugation may affect peptide conformational equilibrium [29]. Some therapeutic peptides conjugated to particular molecular entities such as gold and lanthanide nanoparticles can be rendered fully resistant to proteases [30-32]. However, this is not generalizable to all peptides and cargoes. Achieving such high resistance to proteases is particularly difficult to envision in the case of targeting and cell-penetrating peptides since they need to be exposed and able to bind receptors or interact with the cell membrane. Therefore, in the last decade, some of the strategies summarized in this section have been applied to enhance the stability of these peptides. Although some examples have been reported for different enhancement strategies, such as backbone modification [33], in the next sections we focus on the two most commonly used strategies in this context: enantio/retro-enantio isomerization and cyclization (Table 1).

Table 1. Representative enantio/retro-enantio and cyclic targeting and cell-penetrating peptides.

\begin{tabular}{|c|c|c|c|c|c|}
\hline Name & Sequence & Modification & Application & Cargoes & Reference \\
\hline $\begin{array}{l}\text { d-Tat } 49-57 \\
\text { d-Tat } \\
57-49\end{array}$ & $\begin{array}{l}\text { rkkrrqurr } \\
\text { rrrqrrkkr }\end{array}$ & $\begin{array}{c}\text { Enantio } \\
\text { Retro-enantio }\end{array}$ & Cell internalization & $\begin{array}{c}\text { Small molecules, } \\
\text { nanoparticles, proteins, } \\
\text { oligonucleotides }\end{array}$ & {$[34-36]$} \\
\hline D-dfTAT & $\begin{array}{l}\text { ckrkkrrqrrrG } \\
\text { lkkkkrrqrrrG }\end{array}$ & Enantio & Cell internalization & Small molecules & {$[37]$} \\
\hline $\mathrm{D}-\mathrm{R}_{9} \mathrm{~F}_{2} \mathrm{C}$ & rrrrrrrrrffc & Enantio & Cell internalization & Oligonucleotides & {$[38]$} \\
\hline THRre & pwvpswmpprht & Retro-enantio & BBB-shuttle & $\begin{array}{l}\text { Small molecules, } \\
\text { nanoparticles }\end{array}$ & {$[39,40]$} \\
\hline DAngiopep & cyeetkfnnrkGrsGGyfft & Retro-enantio & Brain tumor targeting & Micelles & {$[41]$} \\
\hline${ }^{\mathrm{D}} \mathrm{A} 7 \mathrm{R}$ & rpplwta & Retro-enantio & Brain tumor targeting & Liposomes & {$[42]$} \\
\hline${ }^{\mathrm{D}} \mathrm{VS}$ & svafpsyrhrsfwsv & Retro-enantio & Brain tumor targeting & Micelles & {$[43]$} \\
\hline${ }^{\mathrm{D}} \mathrm{CDX}$ & GreirtGraerwsekf & Retro-enantio & $\begin{array}{l}\text { BBB shuttle and brain } \\
\text { tumor targeting }\end{array}$ & Liposomes & {$[15]$} \\
\hline D-FNB & eGakhGltfsGG & Retro-enantio & Tumor targeting & Liposomes & [16] \\
\hline cTAT & $\mathrm{K}(\&) \mathrm{rRrGrKkRrE}(\&)$ & Cyclization & Cell internalization & Proteins & {$[44]$} \\
\hline$(\mathrm{WH})_{5}$ & \&WHWHWHWHWH\& & Cyclization & Cell internalization & $\begin{array}{c}\text { Peptides and } \\
\text { small molecules }\end{array}$ & {$[45]$} \\
\hline $\begin{array}{l}\text { Arginine rich } \\
\text { peptide }(1 b)\end{array}$ & $\begin{array}{c}\text { C(\&)RRRRRRC(\&)RRRR } \\
\text { RRC }(\&)^{*}\end{array}$ & Cyclization & Cell internalization & Oligonucleotides & {$[46]$} \\
\hline
\end{tabular}


Table 1. Cont.

\begin{tabular}{|c|c|c|c|c|c|}
\hline Name & Sequence & Modification & Application & Cargoes & Reference \\
\hline Cyclo(RGDfK) & \&RGDfK\& & Cyclization & Tumor targeting & $\begin{array}{l}\text { Cytotoxic drug monomethyl } \\
\text { auristatin E (MMAE) }\end{array}$ & {$[47]$} \\
\hline EETI 2.5F & $\begin{array}{l}\mathrm{GC}\left(\&_{1}\right) \operatorname{PRPRGDNPLTC}\left(\&_{2}\right) \\
\operatorname{SQDSDC}\left(\&_{3}\right) \operatorname{LAGC}\left(\&_{1}\right) \\
\operatorname{VC}\left(\&_{2}\right) \mathrm{GPNGFC}\left(\&_{3}\right) \mathrm{G}\end{array}$ & Cyclization & Tumor targeting & Small molecules & [48] \\
\hline cKNGRE & K(\&)NGRE(\&) & Cyclization & Tumor targeting & Proteins, liposomes & [49] \\
\hline cA7R & \&CATWLPPR\& & Cyclization & Brain tumor targeting & Liposomes & {$[50]$} \\
\hline $\begin{array}{c}\text { Cyclic } \\
\text { M2pep(RY) }\end{array}$ & $\begin{array}{c}\text { C(\&)GYEQDPWGVRY } \\
\text { WYGC(\&)kkk }\end{array}$ & Cyclization & $\begin{array}{l}\text { Targeting of } \\
\text { tumor-associated } \\
\text { macrophages }\end{array}$ & Small molecules & [51] \\
\hline MiniAp-4 & $(\mathrm{Dap})(\&) \mathrm{KAPETALD}(\&)$ & Cyclization & BBB shuttle & $\begin{array}{c}\text { Proteins, nanoparticles, small } \\
\text { molecules }\end{array}$ & {$[52]$} \\
\hline
\end{tabular}

Cyclic peptide nomenclature was adapted from [53] * Trifunctional chemical scaffold.

\section{Enantio and Retro-Enantio Isomerizations Enhance Targeting Efficiency by Increasing Resistance against Proteolytic Degradation}

\subsection{Enantio/Retro-Enantio Cell Penetrating Peptides}

D-amino acids have long been used to study the relevance of peptide 3D structure in peptide internalization. Prochiantz and collaborators, looking for the penetration mechanism of a 16 L-amino acid transcription factor fragment of Antennapedia, demonstrated the successful internalization of its D-version [54]. The fact that both L- and D-peptides could internalize in rat cortical-striatal E15 cells at $37{ }^{\circ} \mathrm{C}$ and $4{ }^{\circ} \mathrm{C}$ indicated that the internalization mechanism was not dependent on a chiral receptor. In this study, L-peptide was already observed to be more sensitive to proteolytic degradation at the higher temperature tested. Soon after, Wender, Futaki, and respective collaborators reported the potential of enantio isomers of arginine-rich cell-penetrating peptides (CPPs), which eventually became one of the most studied CPP families [34,55]. The efficient transport of these peptides is due to the electrostatic interactions between the positively charged arginine side chains and the negatively charged phospholipid membrane. In the pioneering study by Wender and coworkers, the D-versions (enantio and retro-enantio) of the arginine-rich membrane permeable HIV-1 Tat (49-57) were internalized in Jurkat cells more efficiently than the L-versions (parent and enantio) in the presence of $2 \%$ fetal bovine serum [34]. Under these conditions, the enantio version displayed a 3-fold higher cellular uptake than the parent peptide while in the absence of serum the uptake was equivalent, indicating that the chirality was not relevant for cellular uptake and that the higher internalization was due to the protease resistance of the D-version. Similar results were obtained by Futaki and collaborators, confirming the potential of the D-isomerization technique in CPPs [55]. Since then, this strategy has been applied to enhance the potential of many CPPs as drug delivery vectors. Remarkably, the protease resistance of the peptides is relevant not only to preserve the integrity of the peptide before reaching the cell membrane but also to enhance endosomal escape and intracellular fate [37]. Although several internalization mechanisms of CPPs have been reported, in endocytic pathways, hydrolytic resistance is clearly advantageous for resisting endosomal proteases and facilitating endosomal escape (Figure 2A). 


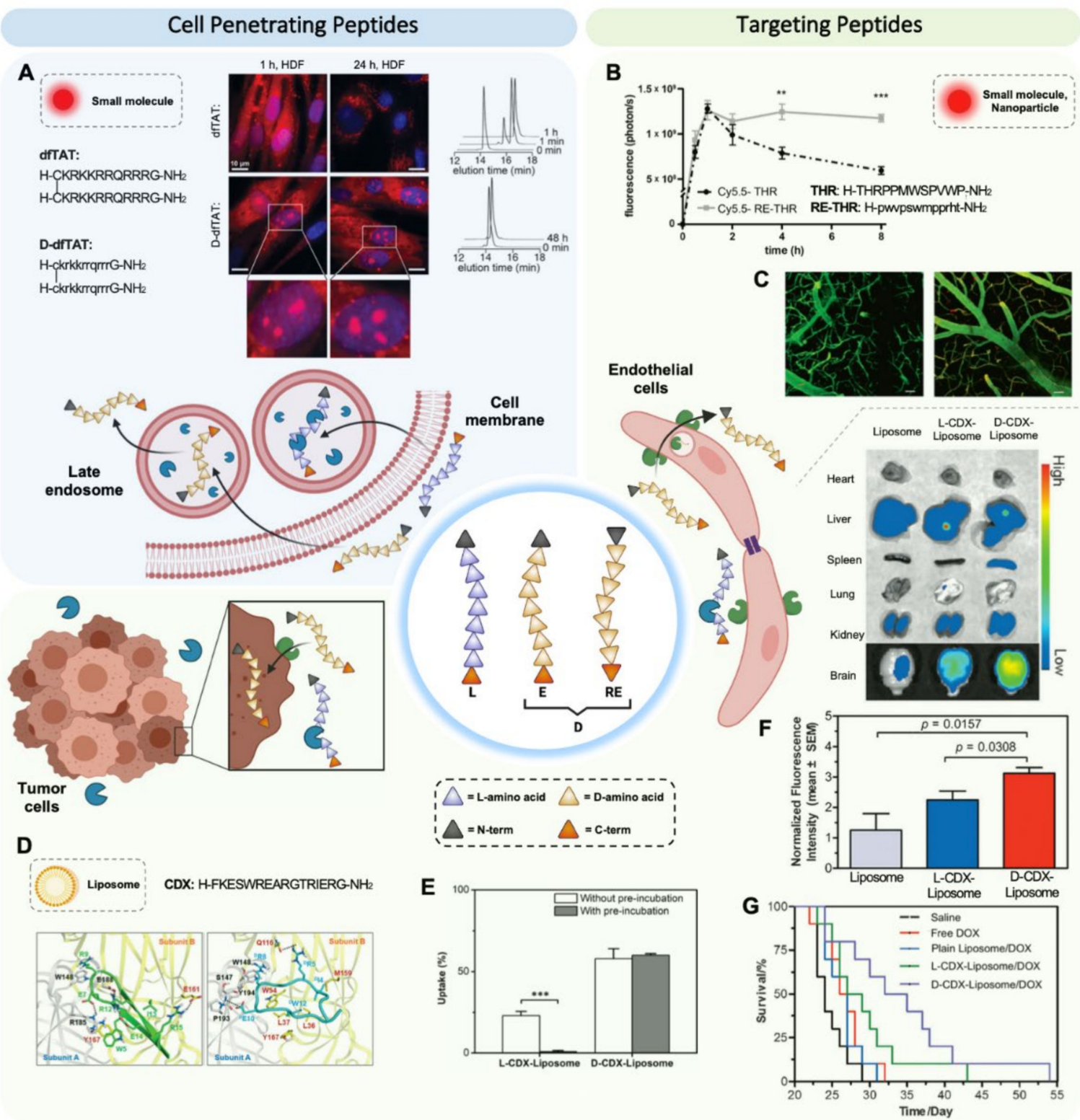

Figure 2. Enantio and retro-enantio isomerization enhance transport and targeting efficiency. (A) Cellular distribution of dfTAT and D-dfTAT immediately after delivery and after $24 \mathrm{~h}$. Fluorescence images are overlays of the TMR (red) and Hoechst (blue) emissions (scale bars $=10 \mu \mathrm{m}$ ) (left). HPLC chromatograms of dfTAT and D-dfTAT upon treatment with trypsin (right), adapted from [37], Elsevier 2017. (B) In vivo fluorescence signal of the THR peptide in mice. Deviations represented as standard error mean. Unpaired t student test: ${ }^{* *} p<0.01$, ${ }^{* * *} p<0.001$, adapted with permission from [39], John Wiley \& Sons, 2015. (C) Intravital two-photon microscopy images of mice brains after injection of "naked" quantum dots (left) or QDs labeled with retro-enantio peptide (right) [39]. (D) Representation of the different binding modes of L-CDX (A, green) and D-CDX (B, aqua) with $\alpha 7 \mathrm{nAChR}$. The subunit A of the receptor is shown in grey and subunit B in yellow. Residues involved in binding are represented with sticks, adapted with permission from [15], John Wiley \& Sons, 2015. (E) Brain capillary endothelial cells uptake of CDX peptide-modified liposomes with and without preincubation in mouse serum. Quantitative cellular uptake by using flow cytometry [15]. (F) Ex vivo fluorescence quantification of brain and other organs of mice $8 \mathrm{~h}$ after injection of rhodamine B-labeled plain liposomes, L-CDX-liposomes, and D-CDX-liposomes (top). In vivo normalized fluorescence intensity of brain with biodistribution of rhodamine B-labeled D-CDX-liposomes, L-CDX-liposomes, and plain liposomes (bottom) [15]. (G) Survival plot of nude mice bearing intracranial U87 tumors. Mice that received four doses of D-CDX or L-CDX-modified liposomes encapsulating doxorubicin (DOX) survived significantly longer than the control groups that received saline [15]. 
CPPs stand as a versatile and powerful tool for enhancing the delivery of a wide variety of therapeutic cargoes. For instance, Liu et al. designed a chlorin gold nanorod derivatized with a D-rich arginine peptide for treating breast cancer by photothermal/photodynamic therapy [36]. CPPs have also been shown to enhance the cellular uptake of genetic material, including small interfering RNA (siRNA) [35] and RNA mimetics such as phosphorodiamidate morpholino oligomers (PMOs) [38]. D-CPP conjugates were completely stable in human serum for $24 \mathrm{~h}$, while fragmentation of the natural L-CPP conjugates was observed within the first $2 \mathrm{~h}$.

\subsection{Enantio/Retro-Enantio Targeting Peptides}

In contrast with CPPs, the 3D structure of targeting peptides is crucial in their interaction with receptors. Therefore, while CPPs exploit both the enantio and retro-enantio isomerizations, the vast majority of studies on targeting peptides focus on the retro-enantio approach, which aims to preserve side chain orientation. The retro-enantio approach has been used extensively to enhance the efficiency of peptides for the transport of therapeutics across the blood-brain barrier (BBB-shuttle peptides) and peptides targeting brain tumors [39]. This strong focus on brain delivery may be due to the high efficiency of targeting and transcytosis across brain endothelium required to reach brain targets in sufficient amounts [56].

One of the pioneering studies in the application of the retro-enantio approach to targeting peptides in this field, by Giralt and collaborators, aimed to enhance the efficiency of the 12-amino acid peptide THR (THRPPMWSPVWP), which binds the transferrin receptor (TfR1 or CD71) [57]. TfR1 is expressed in high levels on the brain microvasculature and enables transcytosis across the BBB. Although L-THR was able to facilitate the transport into the brain of gold nanoparticles to a limited extent [57], the unconjugated peptide was found to have a half-life of $30 \mathrm{~min}$ upon incubation in serum (Figure 2B) [39]. Three strategies were explored for enhancing the half-life of this peptide: $N$-methylation of most labile peptide bonds and enantio and retro-enantio isomerizations. Half-lives were $12 \mathrm{~h}$ for the $\mathrm{N}$-methylated and above $24 \mathrm{~h}$ for the enantio and retro-enantio versions in human serum. The greater potential of the retro-enantio THR peptide (RE-THR) as a BBB shuttle was corroborated in mice. While the parent peptide and RE-THR conjugated to the fluorophore cyanine5.5 were shown to accumulate in the brain to a similar extent within the first hour, brain concentration of the first decreased by approximately $50 \%$ in $8 \mathrm{~h}$, while the latter remained roughly constant in this time period. These results are consistent with the hypothesis that a small cargo such as cyanine5.5 conjugated at the $N$-terminus of the peptide could offer some protection from fast acting aminopeptidases but could not efficiently protect the sequence from endoproteases. Intravital two-photon microscopy showed that RE-THR was capable of driving quantum dots (QDs) into the brain parenchyma (Figure 2C). The free QDs remained strictly in the intravascular spaces of brain capillary, while RE-THR-conjugated QDs were detected outside brain vessels. Recently, Bukchin et al. corroborated the BBB shuttling efficiency of RE-THR peptide conjugated to amphiphilic polymeric nanoparticles [35].

The retro-enantio strategy has also been applied to Angiopep-2, the most advanced BBB shuttle in clinical trials [41]. Angiopep-2 is formed by 19 amino acids (TFFYGGSRGKRNNFKTEEY) and targets the low-density lipoprotein receptor-related protein 1 (LRP1). This peptide has been extensively used as a BBB shuttle and tumor-targeting peptide since LRP1 is expressed in high levels at the BBB and in several tumors, such as glioblastoma [58]. A retro-enantio isomer of L-Angiopep-2 was designed by Lu and collaborators to enhance its metabolic resistance. Micelles functionalized with retro-enantio Angiopep-2 displayed lower cellular uptake in a brain endothelial cell line than the Lparent peptide, suggesting a lower binding affinity to LRP- 1 . However, $50 \%$ of the parent peptide was degraded after a $30 \mathrm{~min}$ incubation in rat serum, while the retro-enantio analog displayed nearly no degradation after $8 \mathrm{~h}$ under the same conditions. Aligned with these results, the retro-enantio conjugate generated the highest brain distribution of micelles in 
mice $1 \mathrm{~h}$ and $4 \mathrm{~h}$ post injection. This indicates that, although the micelles might be partially shielding Angiopep-2 from degradation, the retro-enantio version increases its efficiency. Nonetheless, both retro-enantio and L-Angiopep-2 led to similar targeting of micelles in intracranial glioblastoma after 16 days post tumor implantation, which could be attributed to the BBB becoming compromised with the tumor progression in this mouse model, thereby decreasing the relevance of receptor-mediated transcytosis across brain endothelium.

Ying et al. went one step further and showed that the retro-enantio approach could be applied to the L-A7R (ATWLPPR) peptide to achieve significantly higher tumor volume reduction in mice. L-A7R peptide displays a high affinity for vascular endothelial growth factor receptor 2 (VEGFR2) and neuropilin-1 (NRP-1), both of which are overexpressed on glioma and neovasculature [42]. The retro-enantio version (RE-A7R) showed similar affinity to the parent peptide but was barely degraded after a $4 \mathrm{~h}$ incubation in mouse serum, while L-A7R was practically undetectable within $2 \mathrm{~h}$. When PEGylated liposomes were conjugated to each peptide, both conjugates could be efficiently internalized in vitro in glioblastoma (U87) and endothelial cell lines. Nevertheless, preincubation with mouse serum dramatically reduced L-A7R-liposome internalization, while RE-A7R-liposome internalization was not affected. A similar behavior was observed with the targeting ability in BTB/U87 tumor spheroids. These results suggest that the liposome conjugation would not provide effective protection to L-A7R against proteolytic cleavage, emphasizing the relevance of engineering the native peptide. In vivo, RE-A7R-liposome loaded with phenytoin showed around 70\% higher accumulation in subcutaneous U87 tumors in mice than the L -isomer. Importantly this led to a more effective suppression of subcutaneous U87 tumor growth in mice than the L-conjugate. Furthermore, with the retro-enantio isomer, angiogenesis inhibition was also more pronounced ( $82 \%$ and $66 \%$, respectively), and fewer vasculogenic mimicry channels were observed.

An even more compelling proof of the higher efficacy of retro-enantio peptides for brain tumor targeting was provided with a nanotherapy targeted with a retro-enantio version of VS peptide (VSWFSRHRYSPFAVS) [43]. VS targets $\alpha_{6} \beta_{1}$ integrins, which are upregulated in glioma cells, and $\alpha_{\mathrm{v}} \beta_{3}$ integrins, which are overexpressed in cancer cells and neovasculature. In order to test the antitumor efficiency, VS-functionalized PEG-PLA micelles were loaded with doxorubicin and injected in nude mice bearing U87 tumors. Results confirm the potency of this approach in vivo because RE-VS doxorubicin-loaded micelles displayed higher tumor growth inhibitory effects than L-VS peptide-targeted control. Moreover, RE-VS-modified micelles resulted in the longest median survival in mice when compared with L-VS and the control groups: 22.5 for untargeted, 25.5 for L-VS targeted micelles, and 29.0 days for RE-VS targeted micelles.

One of the most complete studies of retro-enantio isomerization success in peptides capable of crossing the BBB and targeting brain tumors, also by Lu and coworkers, is that of L-CDX peptide (Figure 2D) [15]. This peptide targets the nicotine acetylcholine receptors (nAchRs) on the $\mathrm{BBB}$ and brain tumor cells. Receptor-mediated transcytosis of the retro-enantio CDX was higher than the parent peptide when conjugated to a PEGylated liposome. A $4 \mathrm{~h}$ preincubation in rat serum of the L-CDX-liposome conjugate almost nulled its cellular uptake, evidencing the liposome conjugation inefficiency for protection (Figure 2E). Moreover, the retro-enantio CDX version (dubbed D-CDX) displayed full resistance to rat liver lysosomal homogenate, while the L-version disappeared in $15 \mathrm{~min}$. The authors reasoned that resistance to lysosomal degradation may alter intracellular transit of CDX conjugates, resulting in enhanced transcytosis. In addition, while most retro-enantio peptides tend to display lower affinities for their cognate receptor, retro-enantio CDX curiously enhanced its affinity for $\mathrm{nAchR}, 84.5 \mathrm{nM}$ against $441.6 \mathrm{nM}$ of the parent peptide. The authors argued that the higher affinity was due to a different binding mode, supported with molecular dynamics docking (Figure 2D). As a consequence of its higher stability and affinity, the retro-enantio CDX induced a 30\% higher brain distribution compared with the L-analog (Figure 2F). This higher accumulation presumably resulted in a $20 \%$ increase in the median survival life of mice with glioblastoma compared with the L analog, and by $24 \%$ 
compared with the liposome-formulated doxorubicin (Figure 2G). Combined targeting efficiency of D-CDX and D-A7R has recently been confirmed in liposome drug delivery systems [59].

Most retro-enantio peptides have been obtained by isomerization of L-parent peptides. However, D-peptides can also be directly obtained using mirror-image phage display. An example of this in targeting peptides is the D-FNB peptide against the Fn14 receptor, which is overexpressed in many tumor cells [16]. To generate D-FNB, the D-enantiomeric form of the self-stabilized extracellular cysteine-rich domain of Fn14 membrane receptor was synthesized. An L-peptide was subsequently selected via phage display, and the Denantiomer was synthesized. The in vivo antitumor efficacy of paclitaxel-loaded liposomes targeted with D-FNB significantly inhibited tumor growth in a subcutaneous xenograft model and drastically prolonged survival in a lung metastasis mouse model.

Although the retro-enantio approach may be capable of enhancing metabolic stability while maintaining biological activity, it is not a universally applicable strategy in targeting peptides since affinity for target receptors is often decreased. Mao et al. applied the enantio and retro-enantio approach to the AE peptide (FALGEA) to target the epidermal growth factor receptor (EGFR) and the mutation variant III (EGFRvIII) for glioma treatment [60]. The enantio and retro-enantio peptides were clearly more stable in serum incubation than L-AE. However, in terms of affinity, curiously, the enantio AE targeting capability was comparable with that of $\mathrm{L}-\mathrm{AE}\left(\mathrm{K}_{\mathrm{D}}: 2.0 \mu \mathrm{M}\right.$ and $5.0 \mu \mathrm{M}$, respectively), while retro-enantio AE showed a $K_{D}=211 \mu \mathrm{M}$. Although the enantio AE peptide was successfully used to target paclitaxel-loaded micelles, this study among others shows that despite its success, the retro-enantio strategy is not universally applicable, thus emphasizing the need for alternative ways to achieve metabolic stability, such as cyclization.

\section{Cyclization May Enhance Targeting Efficiency Both by Providing High Protease Resistance and High Binding Affinity}

Together with the use of D-amino acids, cyclization is the most common strategy for conferring protease resistance to targeting and cell-penetrating peptides. Although cyclization on its own does not guarantee the same degree of protection as enantio or retro-enantio isomerizations, it may enhance affinity for the target receptor if the binding conformation is stabilized [23]. As explained in Section 2.4, cyclization may decrease protease recognition provided enough rigidity is conferred to prevent a correct fit of the sequence in the enzyme active site.

\subsection{Cyclic Cell Penetrating Peptides}

CPPs do not bind a receptor, but the cyclic structure has been shown to play a crucial role in the membrane partition efficiency and internalization mechanism [19,61]. This idea has recently been exploited by Cardoso, Hackenberger, and collaborators to enhance the activity of arginine-rich CPPs such as TAT. Cyclic versions of these peptides enhanced non-endocytic cellular uptake, improving internalization kinetics [44]. Cyclic TAT peptide entered living cells on average $15 \mathrm{~min}$ earlier than the linear form and showed a higher cell accumulation. This behavior was attributed to the higher separation between guanidinium groups in the cyclic conformation. The cyclization of this arginine-rich peptide not only improved its kinetic performance but also proved to be a suitable strategy for translocating large cargoes such as GFP (Figure 3A,B) and recombinant anti-GFP nanobodies in vitro $[44,62]$. Cyclic TAT experienced at least a 5-fold increase in the percentage of transduced HeLa cells with one of the nanobodies compared with the linear version. Along the same lines, Parang and collaborators applied the cyclization approach to the amphipathic $\mathrm{CPPs}(\mathrm{WH})_{5}$. The cyclic peptide increased the cellular uptake of two different cargoes, the cell-impermeable phosphopeptide GPYEEI and the anti-HIV drug FTC, by 4and 2.6-fold, respectively, compared with the linear peptide, thus proving to be a more efficient molecular transporter [45]. 


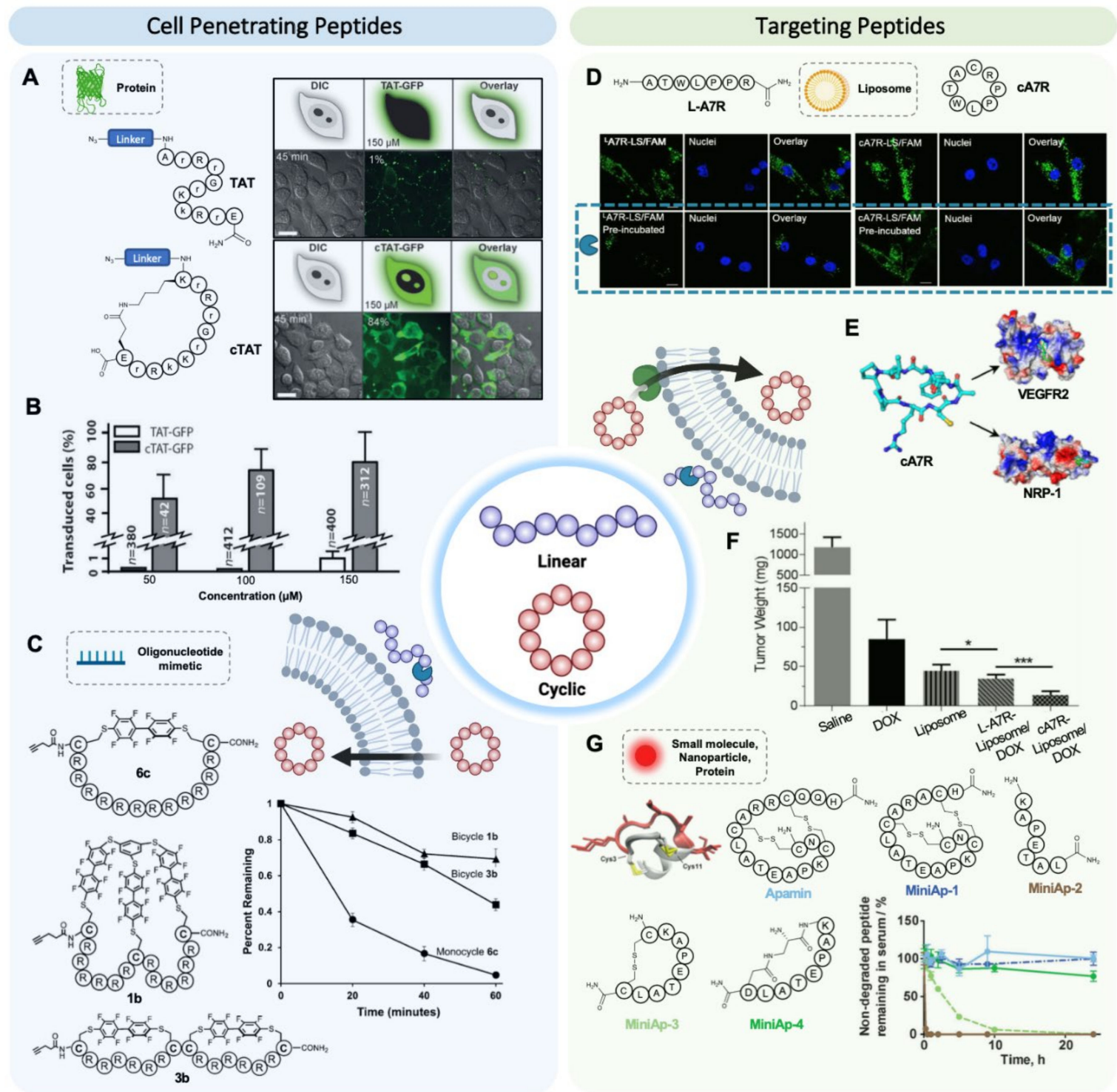

Figure 3. Cyclization of peptides enhances proteolytic stability and thus improves cell penetration or targeting. (A) Chemoselective conjugation via azide-alkyne cycloaddition of GFP to cTAT enhances transduction of living cells. Confocal microscopy images (scale bar $=15 \mu \mathrm{m}$ ) show efficient transduction of $84 \%$ of HeLa cells with the cTAT-GFP conjugate, compared with the $1 \%$ achieved by TAT-GFP, adapted with permission from [44], John Wiley \& Sons, 2014. (B) Quantification of the percentage of transduced cells for 50,100, and $150 \mu \mathrm{M}$ of TAT-GFP and cTAT-GFP [44]. (C) Bicyclic peptides demonstrate enhanced proteolytic stability relative to monocyclic peptides after incubation with trypsin at $37^{\circ} \mathrm{C}$ for up to $1 \mathrm{~h}$, adapted with permission from [46], John Wiley \& Sons, 2018. (D) Cyclic A7R-conjugated liposomes (LS) retain binding capacity to U87 cells after pre-incubation with 50\% mouse serum for $4 \mathrm{~h}$, while binding of L-A7R-LS is dramatically reduced, adapted with permission from [50], Elsevier, 2015. (E) 3D model of cA7R and its binding mode on VEGFR2 and NRP-1 receptors, as simulated by molecular docking [50]. (F) cA7R-conjugated LS loaded with doxorubicin (DOX) shows a very significant reduction in U87-derived xenograft weight in nude mice, confirming the positive influence of the cyclic structure on therapeutic efficacy [50]. (G) 3D representation of MiniAp-4. Proteolytic stability of the BBB shuttle apamin and its four derivatives MiniAp1-4 after incubation with $90 \%$ human serum at $37^{\circ} \mathrm{C}$ for $24 \mathrm{~h}$, adapted with permission from [52], John Wiley \& Sons, 2015.

Taking the cyclic design one step further, Pentelute and coworkers have recently developed bicyclic CPPs for delivering oligonucleotides into the cell nucleus. The peptide macrocyclization links the cysteine sidechains of unprotected peptides with perfluoroaromatic linkers in a stapled peptide mode. The monocyclic and bicyclic peptides improved 
conjugated phosphorodiamidate morpholino oligonucleotide (PMO) exon-skipping activity, both of them roughly 14-fold over the unconjugated PMO in HeLa cells. However, bicyclic peptides demonstrated over 10-fold greater stability than the monocyclic peptide in trypsin (Figure 3C), so the bicyclic versions are expected to have higher activity in vivo [46]. The higher shielding of the bicyclic analog is most likely due to the length of the sequence, the conformation of which is not stabilized enough in the monocyclic version.

\subsection{Cyclic Targeting Peptides}

Cyclization may also enhance the efficiency in targeting peptides. This enhancement is not only due to an increased resistance to proteases but also to a higher affinity for the target receptor, originating from the stabilization of the binding conformation. Although contribution to the targeting efficiency from each one of these phenomena is often not dissected, experiments across several studies illustrate the relevance of cyclization in targeting efficiency.

One of the first and most studied receptor-targeting peptides is RGD (Arg-Gly-Asp). This sequence presents a high affinity towards integrins, a large family of cell adhesion receptors that are widely used in cancer targeting due to their abundance on tumor cells and vasculature [63,64]. The RGD sequence was first identified in the fibrinogen protein [65], and since then, many variants have been developed. The most commonly used variant is a 5-residue cyclic peptide, RGDfK, with enhanced affinity and stability [66]. Liu et al. have recently generated dual-cyclic RGD-peptide derivatives with increased selectivity for targeting monomethyl auristatin E (MMAE) to tumor cells. These peptide-drug conjugates display 2-fold higher cytotoxicity than unmodified MMAE [47]. The RGD motif has also been incorporated into larger peptide structures such as knottins, whose highly constrained structure also confers high proteolytical stability. Cochran and collaborators obtained the engineered knottin EETI 2.5F, with high selectivity for integrin receptors, which provided outstanding imaging contrast for mouse cerebellar medulloblastoma [48]. This same peptide conjugated to gemcitabine proved to be a potent inhibitor of brain, breast, ovarian, and pancreatic cancer cell lines in vitro [67].

A well-studied example of the favorable conformation-locking mediated by cyclization includes the NGR sequence. This tripeptide targets CD13, a tumor marker associated with the myeloid linage. Molecular dynamic simulations indicate that the turn induced by cyclization populates the receptor-binding conformation, enhancing affinity [68]. To support this simulation, a cyclic version of this peptide with a disulfide bridge (CNGRC) and the linear version GNGRG were conjugated to tumor necrosis factor alfa (TNF $\alpha$ ) and administrated to mice bearing B16F1 melanoma. The efficacy of the cyclic peptide was 10fold that of the linear one. These results were attributed to the higher affinity and metabolic stability of the more rigid cyclic peptide, although the contribution of each mechanism was not dissected. More recently, Dreher and collaborators synthesized the cyclic peptide cKNGRE, in which the $N$-terminus was linked to the side chain of glutamate on resin forming a side chain-to-tail lactam bridge [49]. When conjugated to temperature-sensitive liposomes, the cyclic peptide resulted in a 3.5-fold higher affinity than the linear one. The fluorescently labelled cyclic analog also had a dramatically higher capacity to penetrate HT-1080 cells. Although the protease resistance of the peptides was not evaluated, the in vitro imaging tests were carried out in serum ( $30 \mathrm{~min}$ incubation). Therefore, the higher fluorescence signal may be partly attributed to the higher stability of cyclic peptides.

Cyclization has also been applied to longer peptides such as the heptapeptide A7R (ATWLPPR), which binds two glioma markers, VEGFR2 and NRP-1 (Figure 3E) [42]. Lu and coworkers showed that the cyclic version of L-A7R could enhance the anti-glioblastoma effect in vivo by conjugating it to doxorubicin-loaded liposomes [50]. The L-A7R peptide is fully degraded within $2 \mathrm{~h}$ upon incubation in mouse serum. Conversely, head-to-tail cyclization enhanced the lifetime of this peptide up to $12 \mathrm{~h}$. In vitro, both linear and cyclic peptides improved liposome uptake in U87 glioma cells and different kinds of endothelial cells. In contrast, after incubation in serum, while the performance of the cyclic peptide conjugate 
was unaltered, the one of the linear peptide conjugates was clearly decreased (Figure 3D). When the liposomes were loaded with doxorubicin, the cA7R constructs exhibited higher anti-tumor and anti-angiogenic effects in nude mice U87 xenografts (Figure 3F).

Another clear example of the improved targeting capacity of a long cyclic peptide is embodied by the M2pep peptide (YEQDPWGVKWWY). M2pep targets M2 tumorassociated macrophages (TAM), which promote cancer proliferation by suppressing the immune response and stimulating angiogenesis and tumor growth, thus being a potential target for cancer therapies. [69]. Linear M2pep selectively internalizes in M2 macrophages but in no other leukocytes. Upon fusion with the proapoptotic KLA peptide, M2pep reduces the TAM population, prolonging median survival in a murine colon carcinoma model [70]. Nevertheless, low binding affinity and serum stability limit its efficacy as targeting moiety. In a follow-up study, two metabolically stable variants were synthetized: a C-acetylated version (AcM2pep(RY), which was fully degraded within $8 \mathrm{~h}$, and a headto-tail cyclized variant (M2pep(RY)) with a half-life beyond $24 \mathrm{~h}$ in serum [51]. The latter was able to promote significantly higher uptake of the fluorescent dye sulfoCy5 in M2-like TAMs, both in colon and mammary carcinoma models.

Cyclic peptides have also proven to be superior BBB shuttles that selectively enhance the delivery of cargoes into the brain [56,71,72]. A prominent example is that of apamin (CNCKAPETALCARRCQQH), a naturally occurring bicyclic peptide in bee venom that can circumvent the BBB and deliver several cargoes [71,73]. The main problem with the bicyclic natural peptide as a targeting moiety is its neurotoxicity and high immunogenicity. This is why several analogs (MiniAp-1 to 4) were synthesized mimicking the region in the peptide involved in BBB transport and not originating toxicity (Figure 3G) [52]. While the half-life of apamin in human serum was over $24 \mathrm{~h}$, the half-life corresponding to the linear analog was as low as $5 \mathrm{~min}$ (Figure 3G). A monocyclic version with a disulfide bridge had an intermediate half-life of roughly $3 \mathrm{~h}$. Remarkably, by simply replacing the disulfide by a lactam bridge, bridging the side chains of an $\mathrm{N}$-terminal diaminopropionic acid and a $C$-terminal aspartic acid, the half-life increased beyond $24 \mathrm{~h}$, close to that of apamin and a bicyclic analog. The lactam-bridged MiniAp-4 displayed higher BBB permeability than apamin and negligible toxicity and immunogenicity. MiniAp-4 is capable of enhancing the transport of GFP, imaging quantum dots, and gold nanoparticles in a cell-based model of the BBB. Furthermore, this cyclic BBB shuttle improved by 8 -fold the accumulation of a fluorescent probe in mouse brain. Recently, other venom-inspired cyclic BBB shuttles such as miniCTX have been developed [74].

\section{Conclusions and Outlook}

Although many linear all-L peptides have been shown to provide efficient targeting, numerous studies prove that enhancing peptide resistance to proteolysis may further boost targeting and cell penetration. Susceptibility of peptide to degradation depends on the amino acid sequence, cargo, and conjugation site. Among the plethora of strategies developed to enhance the resistance of peptides to proteases, two of them have been applied to targeting peptides and CPPs in the vast majority of cases: enantio/retro-enantio isomerization and cyclization. Full enantio and retro-enantio isomerization intrinsically provides very high resistance to peptide degradation. Interestingly, this may alter intracellular trafficking of peptides, which is especially relevant in CPPs and in shuttle peptides that mediate transcytosis across the blood-brain barrier. Therefore, this isomerization approach has been extensively used in brain-targeted therapeutics, especially addressing brain tumors. Although many successful retro-enantio targeting peptides have been reported, these peptides generally display substantially lower binding affinity. By contrast, cyclization often enhances peptide affinity for its target if the adequate conformation is favored, although increase in protease-resistance may be more limited. By fine-tuning the cyclization strategy, peptides with high selectivity and protease resistance can be engineered.

Despite the numerous examples supporting the use of protease-resistant peptides for targeting and cell penetration, the contribution to protease shielding from sequence 
modification is often difficult to dissect from that provided by conjugation to the cargo. This is due to many studies lacking a clear comparison between the cargo conjugated to both the parent peptide and the "chemically enhanced" version. In the case of the cyclic peptides, there is an additional factor to be taken into account: the effect of cyclization on affinity. To this end, more data on the stability and the affinity of free and conjugated peptides should be provided. Additionally, as it has been recently noted [6], assays to assess peptide stability should be homogenized to enable comparison across studies.

Overall, in recent years numerous studies have proven that modifications increasing protease resistance can significantly enhance the efficiency of targeting and cell penetration peptides, both in cells and in vivo. A careful choice of controls and conditions in future studies will facilitate more accurate comparisons.

Author Contributions: Conceptualization, B.O.-S.; investigation, M.C.L., Y.A., E.P., A.R., R.L.; writing-original draft preparation, M.C.L., Y.A., E.P., A.R., R.L., B.O.-S.; writing-review and editing, M.C.L., Y.A., R.L., B.O.-S.; supervision, R.L., B.O.-S.; funding acquisition, B.O.-S. All authors have read and agreed to the published version of the manuscript.

Funding: B.O.-S. acknowledges support from "la Caixa" Foundation (ID 100010434) and from the European Union's Horizon 2020 research and innovation program under the Marie SkłodowskaCurie grant agreements No 847648 (fellowship LCF/BQ/PR21/11840002) and No 844441; from the MCIN/AEI/ 10.13039/501100011033 grant No PID2020-117486RA-I00; and from Universitat Ramon Llull grant No 2021-URL-Proj-028. R.L. is recipient of an FPU fellowship, grant No FPU19/03216, funded by MCIN/AEI/ 10.13039/501100011033. We acknowledge support from the Agència de Gestió d'Ajuts Universitaris i de Recerca (Generalitat de Catalunya) under the grant agreement SGR 2017 1559. Some images in Figures 2 and 3 in this article were created with BioRender.

Institutional Review Board Statement: Not applicable.

Informed Consent Statement: Not applicable.

Data Availability Statement: Not applicable.

Conflicts of Interest: The authors declare no conflict of interest.

$\begin{array}{ll}\text { Abbreviations } \\ \text { BBB } & \text { Blood-brain barrier } \\ \text { CPP } & \text { Cell penetrating peptide } \\ \text { DOX } & \text { Doxorubicin } \\ \text { EGFR } & \text { Epidermal growth factor receptor } \\ \text { EGFRvIII } & \text { Epidermal growth factor receptor mutation variant III } \\ \text { FDA } & \text { Food and Drug Administration } \\ \text { FTC } & 2^{\prime}, 3^{\prime} \text {-dideoxy-5-fluoro-3'-thiacytidine (Emtricitabine) } \\ \text { GFP } & \text { Green Fluorescent Protein } \\ \text { HIV-1 } & \text { Human immunodeficiency virus type I } \\ \text { HPLC } & \text { High-performance liquid chromatography } \\ \text { LS } & \text { Liposomes } \\ \text { MMAE } & \text { Monomethyl auristatin E } \\ \text { nAchRs } & \text { Nicotine acetylcholine receptors } \\ \text { NRP-1 } & \text { Neuropilin-1 receptor } \\ \text { PEG } & \text { Polyethylene glycol } \\ \text { PMO } & \text { Phosphorodiamidate morpholino oligonucleotide } \\ \text { QD } & \text { Quantum dot } \\ \text { RCM } & \text { Ring-closing metathesis } \\ \text { RE } & \text { Retro-enantio } \\ \text { siRNA } & \text { Small interfering RNA } \\ \text { TAM } & \text { Tumor-associated macrophages } \\ \text { TfR1 } & \text { Transferrin receptor } \\ \text { VEGFR2 } & \text { Vascular endothelial growth factor receptor 2 }\end{array}$




\section{References}

1. Davenport, A.P.; Scully, C.C.G.; de Graaf, C.; Brown, A.J.H.; Maguire, J.J. Advances in therapeutic peptides targeting G proteincoupled receptors. Nat. Rev. Drug Discov. 2020, 19, 389-413. [CrossRef]

2. Brayden, D.J.; Hill, T.A.; Fairlie, D.P.; Maher, S.; Mrsny, R.J. Systemic delivery of peptides by the oral route: Formulation and medicinal chemistry approaches. Adv. Drug Deliv. Rev. 2020, 157, 2-36. [CrossRef] [PubMed]

3. Mathur, D.; Prakash, S.; Anand, P.; Kaur, H.; Agrawal, P.; Mehta, A.; Kumar, R.; Singh, S.; Raghava, G.P.S. PEPlife: A Repository of the Half-life of Peptides. Sci. Rep. 2016, 6, 1-7. [CrossRef]

4. Dissanayake, S.; Denny, W.A.; Gamage, S.; Sarojini, V. Recent developments in anticancer drug delivery using cell penetrating and tumor targeting peptides. J. Control. Release 2017, 250, 62-76. [CrossRef] [PubMed]

5. Khatri, B.; Nuthakki, V.R.; Chatterjee, J. Strategies to Enhance Metabolic Stabilities. Methods Mol. Biol. 2019, 2001, 17-40. [CrossRef] [PubMed]

6. Cavaco, M.; Andreu, D.; Castanho, M.A.R.B. The Challenge of Peptide Proteolytic Stability Studies: Scarce Data, Difficult Readability, and the Need for Harmonization. Angew. Chemie Int. Ed. 2021, 60, 1686-1688. [CrossRef]

7. Pelay-gimeno, M.; Glas, A.; Koch, O.; Grossmann, T.N. Structure-Based Design of Inhibitors of Protein-Protein Interactions: Mimicking Peptide Binding Epitopes. Angewandte 2015, 54, 8896-8927. [CrossRef]

8. Di, L. Strategic Approaches to Optimizing Peptide ADME Properties. AAPS J. 2015, 17, 134-143. [CrossRef]

9. Lenci, E.; Trabocchi, A. Peptidomimetic toolbox for drug discovery. Chem. Soc. Rev. 2020, 49, 3262-3277. [CrossRef] [PubMed]

10. Avan, I.; Hall, C.D.; Katritzky, A.R. Peptidomimetics via modifications of amino acids and peptide bonds. Chem. Soc. Rev. 2014, 43, 3575. [CrossRef]

11. Chatterjee, J.; Rechenmacher, F.; Kessler, H. N -Methylation of Peptides and Proteins: An Important Element for Modulating Biological Functions. Angew. Chemie Int. Ed. 2013, 52, 254-269. [CrossRef]

12. Niehaus, E.-M.; Janevska, S.; von Bargen, K.W.; Sieber, C.M.K.; Harrer, H.; Humpf, H.-U.; Tudzynski, B. Apicidin F: Characterization and Genetic Manipulation of a New Secondary Metabolite Gene Cluster in the Rice Pathogen Fusarium fujikuroi. PLoS ONE 2014, 9, e103336. [CrossRef]

13. Laird, D.W.; LaBarbera, D.V.; Feng, X.; Bugni, T.S.; Harper, M.K.; Ireland, C.M. Halogenated cyclic peptides isolated from the sponge Corticium sp. J. Nat. Prod. 2007, 70, 741-746. [CrossRef] [PubMed]

14. Meng, H.; Kumar, K. Antimicrobial activity and protease stability of peptides containing fluorinated amino acids. J. Am. Chem. Soc. 2007, 129, 15615-15622. [CrossRef]

15. Wei, X.; Zhan, C.; Shen, Q.; Fu, W.; Xie, C.; Gao, J.; Peng, C.; Zheng, P.; Lu, W. A D-peptide ligand of nicotine acetylcholine receptors for brain-targeted drug delivery. Angew. Chemie Int. Ed. 2015, 54, 3023-3027. [CrossRef]

16. Li, Z.; Xie, J.; Peng, S.; Liu, S.; Wang, Y.; Lu, W.; Shen, J.; Li, C. Novel Strategy Utilizing Extracellular Cysteine-Rich Domain of Membrane Receptor for Constructing d -Peptide Mediated Targeted Drug Delivery Systems: A Case Study on Fn14. Bioconjug. Chem. 2017, 28, 2167-2179. [CrossRef]

17. Hervé, M.; Maillère, B.; Mourier, G.; Texier, C.; Leroy, S.; Ménez, A. On the immunogenic properties of retro-inverso peptides. Total retro- inversion of T-cell epitopes causes a loss of binding to MHC II molecules. Mol. Immunol. 1997, 34, 157-163. [CrossRef]

18. Chow, H.Y.; Zhang, Y.; Matheson, E.; Li, X. Ligation Technologies for the Synthesis of Cyclic Peptides. Chem. Rev. 2019, 119, 9971-10001. [CrossRef] [PubMed]

19. Dougherty, P.G.; Sahni, A.; Pei, D. Understanding Cell Penetration of Cyclic Peptides. Chem. Rev. 2019, 119, $10241-10287$. [CrossRef]

20. Malde, A.K.; Hill, T.A.; Iyer, A.; Fairlie, D.P. Crystal Structures of Protein-Bound Cyclic Peptides. Chem. Rev. 2019, 119, 9861-9914. [CrossRef] [PubMed]

21. Reguera, L.; Rivera, D.G. Multicomponent Reaction Toolbox for Peptide Macrocyclization and Stapling. Chem. Rev. 2019, 119, 9836-9860. [CrossRef]

22. Tyndall, J.D.A.; Nall, T.; Fairlie, D.P. Proteases Universally Recognize? Strands in Their Active Sites. ChemInform 2005, 36, 973-1000. [CrossRef]

23. Joo, S.-H. Cyclic Peptides as Therapeutic Agents and Biochemical Tools. Biomol. Ther. 2012, 20, 19-26. [CrossRef]

24. Bird, G.H.; Christian Crannell, W.; Walensky, L.D. Chemical Synthesis of Hydrocarbon-Stapled Peptides for Protein Interaction Research and Therapeutic Targeting. Curr. Protoc. Chem. Biol. 2011, 3, 99-117. [CrossRef]

25. Qian, Z.; Rhodes, C.A.; McCroskey, L.C.; Wen, J.; Appiah-Kubi, G.; Wang, D.J.; Guttridge, D.C.; Pei, D. Enhancing the Cell Permeability and Metabolic Stability of Peptidyl Drugs by Reversible Bicyclization. Angew. Chemie Int. Ed. 2017, 56, 1525-1529. [CrossRef] [PubMed]

26. Wu, Y.; Lu, D.; Jiang, Y.; Jin, J.; Liu, S.; Chen, L.; Zhang, H.; Zhou, Y.; Chen, H.; Nagle, D.G.; et al. Stapled Wasp Venom-Derived Oncolytic Peptides with Side Chains Induce Rapid Membrane Lysis and Prolonged Immune Responses in Melanoma. J. Med. Chem. 2021, 64, 5802-5815. [CrossRef] [PubMed]

27. Montgomery, J.E.; Donnelly, J.A.; Fanning, S.W.; Speltz, T.E.; Shangguan, X.; Coukos, J.S.; Greene, G.L.; Moellering, R.E. Versatile Peptide Macrocyclization with Diels-Alder Cycloadditions. J. Am. Chem. Soc. 2019, 141, 16374-16381. [CrossRef] [PubMed]

28. Bechtler, C.; Lamers, C. Macrocyclization strategies for cyclic peptides and peptidomimetics. RSC Med. Chem. 2021, 12, 1325-1351. [CrossRef] [PubMed] 
29. Draper, S.R.E.; Lawrence, P.B.; Billings, W.M.; Xiao, Q.; Brown, N.P.; Bécar, N.A.; Matheson, D.J.; Stephens, A.R.; Price, J.L. Polyethylene Glycol Based Changes to $\beta$-Sheet Protein Conformational and Proteolytic Stability Depend on Conjugation Strategy and Location. Bioconjug. Chem. 2017, 28, 2507-2513. [CrossRef] [PubMed]

30. Kalimuthu, K.; Lubin, B.C.; Bazylevich, A.; Gellerman, G.; Shpilberg, O.; Luboshits, G.; Firer, M.A. Gold nanoparticles stabilize peptide-drug-conjugates for sustained targeted drug delivery to cancer cells. J. Nanobiotechnology 2018, 16, 1-13. [CrossRef]

31. Niu, F.; Yan, J.; Ma, B.; Li, S.; Shao, Y.; He, P.; Zhang, W.; He, W.; Ma, P.X.; Lu, W. Lanthanide-doped nanoparticles conjugated with an anti-CD33 antibody and a p53-activating peptide for acute myeloid leukemia therapy. Biomaterials 2018, 167, 132-142. [CrossRef]

32. Yan, J.; He, W.; Yan, S.; Niu, F.; Liu, T.; Ma, B.; Shao, Y.; Yan, Y.; Yang, G.; Lu, W.; et al. Self-Assembled Peptide-Lanthanide Nanoclusters for Safe Tumor Therapy: Overcoming and Utilizing Biological Barriers to Peptide Drug Delivery. ACS Nano 2018, 12, 2017-2026. [CrossRef] [PubMed]

33. Mascarin, A.; Valverde, I.E.; Mindt, T.L. Radiolabeled analogs of neurotensin (8-13) containing multiple 1,2,3-triazoles as stable amide bond mimics in the backbone. Medchemcomm 2016, 7, 1640-1646. [CrossRef]

34. Wender, P.A.; Mitchell, D.J.; Pattabiraman, K.; Pelkey, E.T.; Steinman, L.; Rothbard, J.B. The design, synthesis, and evaluation of molecules that enable or enhance cellular uptake: Peptoid molecular transporters. Proc. Natl. Acad. Sci. USA 2000, 97, 13003-13008. [CrossRef]

35. Snyder, E.L.; Meade, B.R.; Saenz, C.C.; Dowdy, S.F. Treatment of terminal peritoneal carcinomatosis by a transducible p53activating peptide. PLoS Biol. 2004, 2, 186-193. [CrossRef]

36. Liu, L.; Xie, H.J.; Mu, L.M.; Liu, R.; Su, Z.B.; Cui, Y.N.; Xie, Y.; Lu, W.L. Functional chlorin gold nanorods enable to treat breast cancer by photothermal/photodynamic therapy. Int. J. Nanomedicine 2018, 13, 8119-8135. [CrossRef] [PubMed]

37. Najjar, K.; Erazo-Oliveras, A.; Brock, D.J.; Wang, T.Y.; Pellois, J.P. An L- to D-amino acid conversion in an endosomolytic analog of the cell-penetrating peptide TAT influences proteolytic stability, endocytic uptake, and endosomal escape. J. Biol. Chem. 2017, 292, 847-861. [CrossRef]

38. Youngblood, D.S.; Hatlevig, S.A.; Hassinger, J.N.; Iversen, P.L.; Moulton, H.M. Stability of cell-penetrating peptide-morpholino oligomer conjugates in human serum and in cells. Bioconjug. Chem. 2007, 18, 50-60. [CrossRef]

39. Prades, R.; Oller-Salvia, B.; Schwarzmaier, S.M.; Selva, J.; Moros, M.; Balbi, M.; Grazú, V.; De La Fuente, J.M.; Egea, G.; Plesnila, N.; et al. Applying the retro-enantio approach to obtain a peptide capable of overcoming the blood-brain barrier. Angew. Chemie Int. Ed. 2015, 54, 3967-3972. [CrossRef] [PubMed]

40. Bukchin, A.; Sanchez-Navarro, M.; Carrera, A.; Teixidó, M.; Carcaboso, A.M.; Giralt, E.; Sosnik, A. Amphiphilic Polymeric Nanoparticles Modified with a Retro-Enantio Peptide Shuttle Target the Brain of Mice. Chem. Mater. 2020, 32, 7679-7693. [CrossRef]

41. Wei, X.; Zhan, C.; Chen, X.; Hou, J.; Xie, C.; Lu, W. Retro-inverso isomer of angiopep-2: A stable d -peptide ligand inspires brain-targeted drug delivery. Mol. Pharm. 2014, 11, 3261-3268. [CrossRef]

42. Ying, M.; Shen, Q.; Liu, Y.; Yan, Z.; Wei, X.; Zhan, C.; Gao, J.; Xie, C.; Yao, B.; Lu, W. Stabilized Heptapeptide A7R for Enhanced Multifunctional Liposome-Based Tumor-Targeted Drug Delivery. ACS Appl. Mater. Interfaces 2016, 8, 13232-13241. [CrossRef] [PubMed]

43. Ren, Y.; Zhan, C.; Gao, J.; Zhang, M.; Wei, X.; Ying, M.; Liu, Z.; Lu, W. A d -Peptide Ligand of Integrins for Simultaneously Targeting Angiogenic Blood Vasculature and Glioma Cells. Mol. Pharm. 2017, 15, 592-601. [CrossRef] [PubMed]

44. Nischan, N.; Herce, H.D.; Natale, F.; Bohlke, N.; Budisa, N.; Cardoso, M.C.; Hackenberger, C.P.R. Covalent attachment of cyclic TAT peptides to GFP results in protein delivery into live cells with immediate bioavailability. Angew. Chemie Int. Ed. 2014, 54, 1950-1953. [CrossRef]

45. Shirazi, A.N.; Mozaffari, S.; Sherpa, R.T.; Tiwari, R.; Parang, K. Efficient intracellular delivery of cell-impermeable cargo molecules by peptides containing tryptophan and histidine. Molecules 2018, 23. [CrossRef] [PubMed]

46. Wolfe, J.M.; Fadzen, C.M.; Holden, R.L.; Yao, M.; Hanson, G.J.; Pentelute, B.L. Perfluoroaryl Bicyclic Cell-Penetrating Peptides for Delivery of Antisense Oligonucleotides. Angew. Chemie 2018, 130, 4846-4849. [CrossRef]

47. Liu, J.; Cheng, X.; Tian, X.; Guan, D.; Ao, J.; Wu, Z.; Huang, W.; Le, Z. Design and synthesis of novel dual-cyclic RGD peptides for $\alpha$ v $\beta 3$ integrin targeting. Bioorganic Med. Chem. Lett. 2019, 29, 896-900. [CrossRef]

48. Moore, S.J.; Hayden Gephart, M.G.; Bergen, J.M.; Su, Y.R.S.; Rayburn, H.; Scott, M.P.; Cochran, J.R. Engineered knottin peptide enables noninvasive optical imaging of intracranial medulloblastoma. Proc. Natl. Acad. Sci. USA 2013, 110, 14598-14603. [CrossRef]

49. Negussie, A.H.; Miller, J.L.; Reddy, G.; Drake, S.K.; Wood, B.J.; Dreher, M.R. Synthesis and in vitro evaluation of cyclic NGR peptide targeted thermally sensitive liposome. J. Control. Release 2010, 143, 265-273. [CrossRef]

50. Ying, M.; Shen, Q.; Zhan, C.; Wei, X.; Gao, J.; Xie, C.; Yao, B.; Lu, W. A stabilized peptide ligand for multifunctional glioma targeted drug delivery. J. Control. Release 2016, 243, 86-98. [CrossRef]

51. Ngambenjawong, C.; Gustafson, H.H.; Pineda, J.M.; Kacherovsky, N.A.; Cieslewicz, M.; Pun, S.H. Serum stability and affinity optimization of an M2 macrophage-targeting peptide (M2pep). Theranostics 2016, 6, 1403-1414. [CrossRef]

52. Oller-Salvia, B.; Sánchez-Navarro, M.; Ciudad, S.; Guiu, M.; Arranz-Gibert, P.; Garcia, C.; Gomis, R.R.; Cecchelli, R.; García, J.; Giralt, E.; et al. MiniAp-4: A Venom-Inspired Peptidomimetic for Brain Delivery. Angew. Chemie 2016, 55, 572-575. [CrossRef] [PubMed] 
53. Spengler, J.; Jiménez, J.C.; Burger, K.; Giralt, E.; Albericio, F. Abbreviated nomenclature for cyclic and branched homo- and hetero-detic peptides. J. Pept. Res. 2005, 65, 550-555. [CrossRef] [PubMed]

54. Derossi, D.; Calvet, S.; Trembleau, A.; Brunissen, A.; Chassaing, G.; Prochiantz, A. Cell internalization of the third helix of the antennapedia homeodomain is receptor-independent. J. Biol. Chem. 1996, 271, 18188-18193. [CrossRef]

55. Futaki, S.; Suzuki, T.; Ohashi, W.; Yagami, T.; Tanaka, S.; Ueda, K.; Sugiura, Y. Arginine-rich peptides. An abundant source of membrane-permeable peptides having potential as carriers for intracellular protein delivery. J. Biol. Chem. 2001, 276, 5836-5840. [CrossRef] [PubMed]

56. Oller-Salvia, B.; Sánchez-Navarro, M.; Giralt, E.; Teixidó, M. Blood-brain barrier shuttle peptides: An emerging paradigm for brain delivery. Chem. Soc. Rev. 2016, 45, 4690-4707. [CrossRef] [PubMed]

57. Prades, R.; Guerrero, S.; Araya, E.; Molina, C.; Salas, E.; Zurita, E.; Selva, J.; Egea, G.; López-Iglesias, C.; Teixidó, M.; et al. Delivery of gold nanoparticles to the brain by conjugation with a peptide that recognizes the transferrin receptor. Biomaterials 2012, 33, 7194-7205. [CrossRef] [PubMed]

58. Ji, X.; Wang, H.; Chen, Y.; Zhou, J.; Liu, Y. Recombinant expressing angiopep-2 fused anti-VEGF single chain Fab (scFab) could cross blood-brain barrier and target glioma. AMB Express 2019, 9, 1-12. [CrossRef]

59. Ying, M.; Zhan, C.; Wang, S.; Yao, B.; Hu, X.; Song, X.; Zhang, M.; Wei, X.; Xiong, Y.; Lu, W. Liposome-Based Systemic Glioma-Targeted Drug Delivery Enabled by All- d Peptides. ACS Appl. Mater. Interfaces 2016, 8, 29977-29985. [CrossRef] [PubMed]

60. Mao, J.; Ran, D.; Xie, C.; Shen, Q.; Wang, S.; Lu, W. EGFR/EGFRvIII Dual-Targeting Peptide-Mediated Drug Delivery for Enhanced Glioma Therapy. ACS Appl. Mater. Interfaces 2017, 9, 24462-24475. [CrossRef] [PubMed]

61. Habault, J.; Poyet, J.L. Recent advances in cell penetrating peptide-based anticancer therapies. Molecules 2019, 24, 927. [CrossRef]

62. Herce, H.D.; Schumacher, D.; Schneider, A.F.L.; Ludwig, A.K.; Mann, F.A.; Fillies, M.; Kasper, M.A.; Reinke, S.; Krause, E.; Leonhardt, H.; et al. Cell-permeable nanobodies for targeted immunolabelling and antigen manipulation in living cells. Nat. Chem. 2017, 9, 762-771. [CrossRef]

63. Cox, D.; Brennan, M.; Moran, N. Integrins as therapeutic targets: Lessons and opportunities. Nat. Rev. Drug Discov. 2010, 9, 804-820. [CrossRef]

64. Asati, S.; Pandey, V.; Soni, V. RGD Peptide as a Targeting Moiety for Theranostic Purpose: An Update Study. Int. J. Pept. Res. Ther. 2019, 25, 49-65. [CrossRef]

65. Pierschbacher, M.D.; Ruoslahti, E. Cell attachment activity of fibronectin can be duplicated by small synthetic fragments of the molecule. Nature 1984, 309, 30-33. [CrossRef] [PubMed]

66. Haubner, R.; Gratias, R.; Diefenbach, B.; Goodman, S.L.; Jonczyk, A.; Kessler, H. Structural and functional aspects of RGDcontaining cyclic pentapeptides as highly potent and selective integrin $\alpha(\mathrm{v}) \beta 3$ antagonists. J. Am. Chem. Soc. 1996, 118, 7461-7472. [CrossRef]

67. Cox, N.; Kintzing, J.R.; Smith, M.; Grant, G.A.; Cochran, J.R. Integrin-Targeting Knottin Peptide-Drug Conjugates Are Potent Inhibitors of Tumor Cell Proliferation. Angew. Chemie Int. Ed. 2016, 55, 9894-9897. [CrossRef] [PubMed]

68. Colombo, G.; Curnis, F.; De Mori, G.M.S.; Gasparri, A.; Longoni, C.; Sacchi, A.; Longhi, R.; Corti, A. Structure-activity relationships of linear and cyclic peptides containing the NGR tumor-homing motif. J. Biol. Chem. 2002, 277, 47891-47897. [CrossRef] [PubMed]

69. Dhabekar, G.; Dandekar, R.; Kingaonkar, A. Role of macrophages in malignancy. Ann. Maxillofac. Surg. 2011, 1, 150. [CrossRef] [PubMed]

70. Cieslewicz, M.; Tang, J.; Yu, J.L.; Cao, H.; Zaèaljeèski, M.; Motoyama, K.; Lieber, A.; Raines, E.W.; Pun, S.H. Targeted delivery of proapoptotic peptides to tumor-associated macrophages improves survival. Proc. Natl. Acad. Sci. USA 2013, 110, 15919-15924. [CrossRef] [PubMed]

71. Oller-Salvia, B.; Teixidó, M.; Giralt, E. From venoms to BBB shuttles: Synthesis and blood-brain barrier transport assessment of apamin and a nontoxic analog. Biopolymers 2013, 100, 675-686. [CrossRef] [PubMed]

72. Teixidó, M.; Zurita, E.; Mendieta, L.; Oller-Salvia, B.; Prades, R.; Tarragó, T.; Giralt, E. Dual system for the central nervous system targeting and blood-brain barrier transport of a selective prolyl oligopeptidase inhibitor. Biopolymers 2013, 100, 662-674. [CrossRef]

73. Wu, J.; Jiang, H.; Bi, Q.; Luo, Q.; Li, J.; Zhang, Y.; Chen, Z.; Li, C. Apamin-Mediated Actively Targeted Drug Delivery for Treatment of Spinal Cord Injury: More Than Just a Concept. Mol. Pharm. 2014, 11, 3210-3222. [CrossRef] [PubMed]

74. Díaz-Perlas, C.; Varese, M.; Guardiola, S.; García, J.; Sánchez-Navarro, M.; Giralt, E.; Teixidó, M. From venoms to BBB-shuttles. MiniCTX3: A molecular vector derived from scorpion venom. Chem. Commun. 2018, 54, 12738-12741. [CrossRef] [PubMed] 